\title{
A new simple method for determining the critical micelle concentration of surfactants using surface plasmon resonance of silver nanoparticles
}

Mohammad Ali Karimi ${ }^{1,2^{*}}$, Malihe Alsadat Mozaheb ${ }^{3,4}$, Abdolhamid Hatefi-Mehrjardi ${ }^{1,2}$, Hossein Tavallali ${ }^{1}$, Abdol Mohammad Attaran ${ }^{1}$ and Roghayeh Shamsi ${ }^{2}$

\begin{abstract}
Background: A new and simple determination method for critical micelle concentration (CMC) has been developed based on surface plasmon resonance (SPR) technique. In the current work, the CMCs for sodium dodecyl sulfate (SDS), cetyl trimethyl ammonium bromide (CTAB), and Triton X-100 (TX-100) were determined in aqueous media by SPR of silver nanoparticles (AgNPs).

Findings: The variation of the absorbance of AgNPs in respect of bulk water is a consequence of the micelles formation from the surfactants monomer, here, SDS, CTAB, and TX-100. Under the optimal experimental conditions, CMCs for SDS, CTAB, and TX-100 using SPR technique were $8.6 \times 10^{-3}, 9.1 \times 10^{-4}$, and $2.6 \times 10^{-4} \mathrm{~mol} \mathrm{~L}^{-1}$, respectively.

Conclusions: The potential application of SPR technique for the CMC determination has been demonstrated in this work. Comparing to the other CMC determination methods, this SPR method is universal, sensitive, and nonadditive; it can be used for the direct measurements of $C M C$ without adding any dyes or fluorescent probes. CMC values of various surfactants including SDS, CTAB, and TX-100 determined by this method are in agreement with those determined by the other methods. The results obtained by our simple method have comparable accuracy with those obtained from more elaborate experiments.
\end{abstract}

Keywords: Critical micellar concentration (CMC), Surfactants, Silver nanoparticles (AgNPs), Surface plasmon resonance (SPR)

\section{Findings}

Introduction

Surfactants are compounds with molecular structure consisting of hydrophilic and hydrophobic parts. These important classes of industrial chemicals are widely used in modern industries. The hydrophilic part consists of an ionic or polar group whereas the hydrophobic part is generally a long hydrocarbon chain. In diluted solutions, the surfactants are found as individual monomers. At a concentration above a critical value, i.e.,

\footnotetext{
*Correspondence: ma_karimi43@yahoo.com

'Department of Chemistry, Payame Noor University, PO Box 19395-4697, Tehran, Iran

${ }^{2}$ Department of Chemistry \&Nanoscience and Nanotechnology Research Laboratory (NNRL), Payame Noor University, PO Box 78185-347, Sirjan, Iran Full list of author information is available at the end of the article
}

critical micelle concentration $(\mathrm{CMC})$, surfactant molecules tend to aggregate forming micelles. At CMC point, some properties of surfactant solutions like conductivity, surface tension, osmotic pressure, absorption, and fluorescence as a function of concentration suffer abrupt changes due to the micelle formation (Tran \& Yu 2005; Van Os et al. 1993).

CMC value of surfactants must be known in many applications like solubilization, stabilization, isolation, crystallization, etc. Therefore, CMC determination as an important characteristic of a surfactant is of great importance. CMC point can be determined by examining the changes in the chemical and physical characteristics of surface activator solutions after increasing their concentrations. Several methods have been reported for 
the determination of CMC such as UV-visible spectrophotometry (Khamis et al. 2005; Mondal \& Ghosh 2012), fluorimetry (Mondal \& Ghosh 2012; Topel et al. 2013; Zhu et al. 2014), infrared spectroscopy (Tran \& Yu 2005), light scattering (Topel et al. 2013), nuclear magnetic resonance (NMR) (Yan \& Palmer 1969), chromatography (Lin \& Lin 2000), sound velocity (Zielinski et al. 1987), calorimetry (Simonović \& Momirović 1997), and electrochemical techniques (Racaud et al. 2010; Nesmerak \& Nemcova 2006).

In the past years, the theory and applications of surface plasmon resonance (SPR) have been discussed by several researchers (Yong et al. 2009; Abdulhalim et al. 2008; Amendola et al. 2010). Several of these applications take advantage of the engineering of silver nanoparticle (AgNP) plasmonic response that depends on their shape, size, dielectric environment, and on mutual electromagnetic interactions among particles in close proximity (Ren \& Tilley 2007). SPR is a powerful technique to retrieve information on optical properties of nanomaterials. Essentially, SPR depends on the optical properties of metal layer and environmental changes, so it is related to charge density oscillation at the interface between them (Homola 2006). Hence, the main potential of SPR is the characterization of medium after the metal layer. Resize of the SPR signal is proportional to the mass of material that has immobilized SPR data, mass and thickness of absorbed layers can be inferred (Pattnaik 2005).

To the best of our knowledge, CMC determination by SPR method using AgNPs has not yet been reported. The aim of this work was to evaluate the possibility of using this method for CMC determination in aqueous solutions.

This paper describes a method for the CMC determination of sodium dodecyl sulfate (SDS), cetyl trimethyl

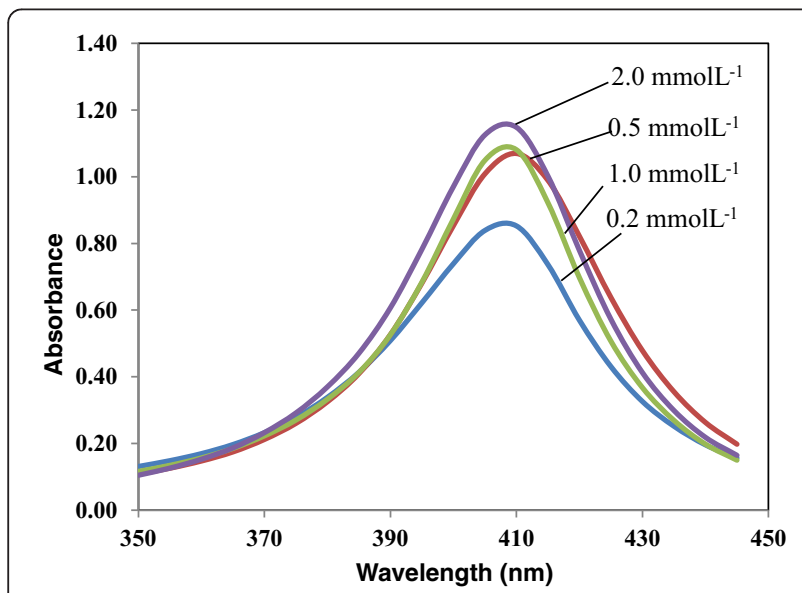

Fig. 1 The effect of silver nitrate concentration on AgNP absorption spectrum ammonium bromide (CTAB), and Triton X-100 (TX$100)$ in aqueous media by SPR of AgNPs. The method is based on the variations observed in the absorbance of AgNPs.

\section{Materials and methods Instruments and reagents}

A GBC UV-Visible Cintra 6 Spectrophotometer model, attached to a Pentium (IV) computer, with 1-cm quartz cell was used for the evaluation of optical characteristics
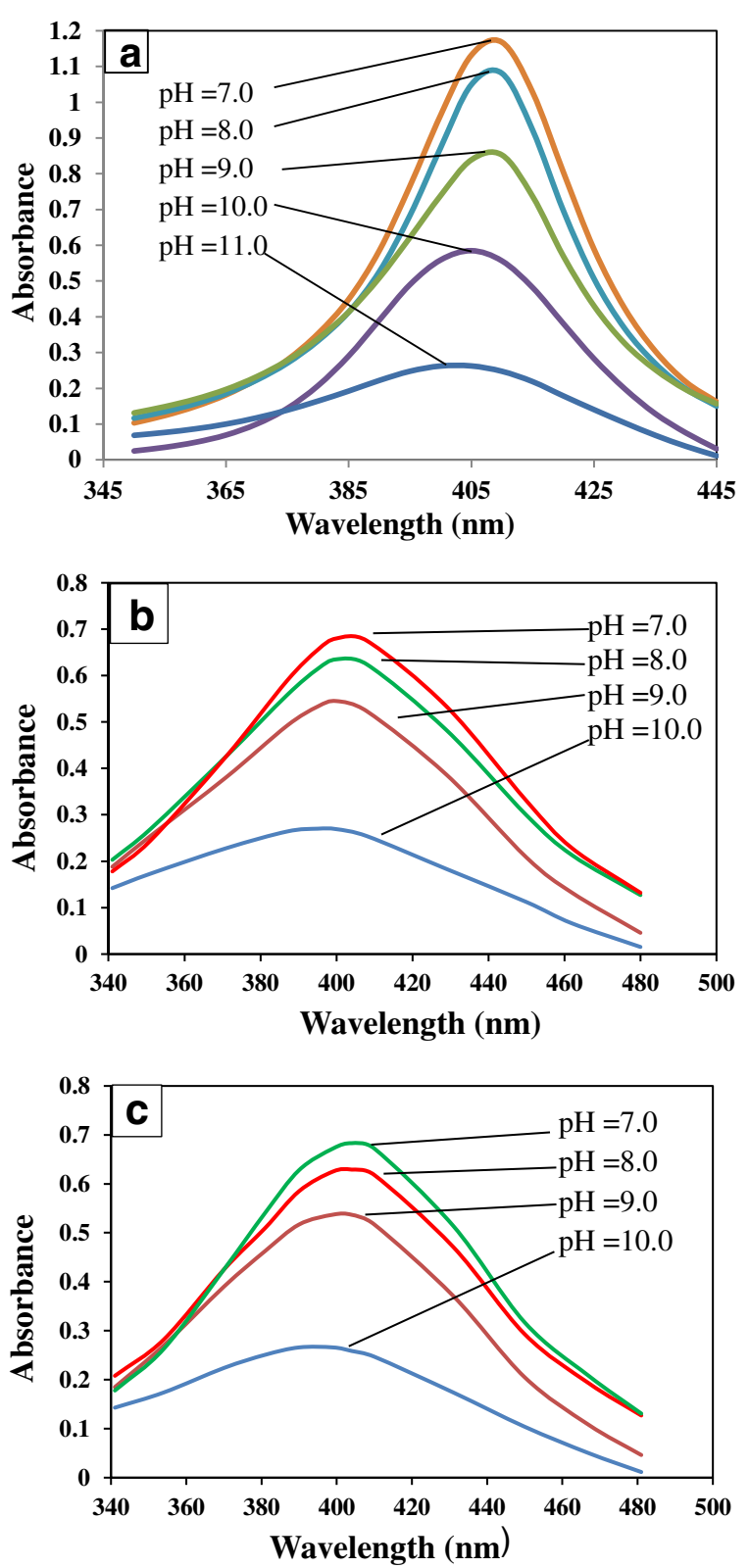

Fig. 2 The SPR spectra of AgNPs at different pHs in the presence of CTAB (a), TX-100 (b), and SDS (c). Conditions: $2.0 \mathrm{~mL} \mathrm{\textrm {AgNO } _ { 3 }}$ $\left(2.0 \times 10^{-3} \mathrm{~mol} \mathrm{~L}^{-1}\right), 1.0 \mathrm{~mL} \mathrm{NaBH} 4\left(1.0 \times 10^{-2} \mathrm{~mol} \mathrm{~L}^{-1}\right), 1.0 \mathrm{~mL}$ of $1.0 \times 10^{-3} \mathrm{~mol} \mathrm{~L}^{-1}$ surfactant and $25^{\circ} \mathrm{C}$ 


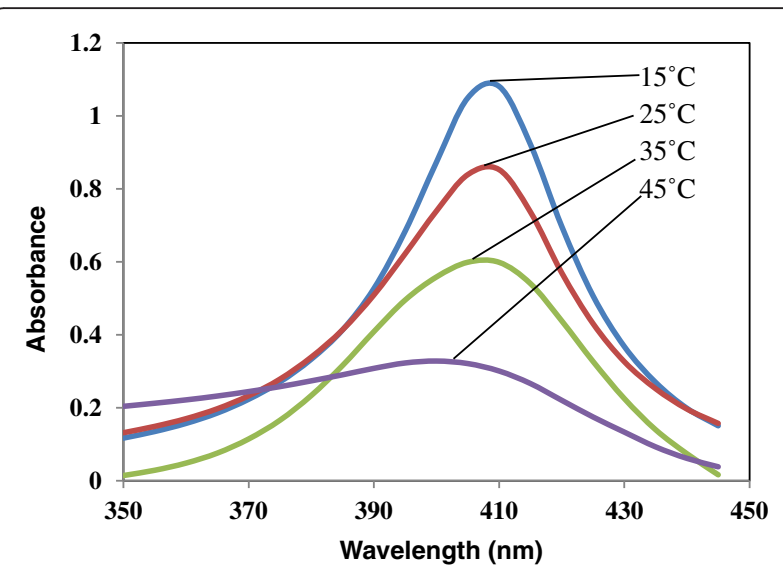

Fig. 3 AgNP absorption spectrum at different temperatures. Conditions as Fig. 2

of the SPR of AgNPs and for recording the spectra data. Metrohm $781 \mathrm{pH}$-meter was used to adjust $\mathrm{pH}$ of the buffered solutions.

All chemicals were of analytical grade and used as received without further purification. Silver nitrate $\left(\mathrm{AgNO}_{3}\right)$, sodium borohydride $\left(\mathrm{NaBH}_{4}\right)$, SDS, CTAB, and TX-100 which are used for the synthesis of AgNPs and CMC determination of surfactants were purchased from Merck. SDS, CTAB, and TX-100 solutions $\left(1.0 \times 10^{-2} \mathrm{~mol} \mathrm{~L}^{-1}\right)$ were prepared by dissolving $0.288,0.364$, and $0.647 \mathrm{~g}$ in water and diluting to $100 \mathrm{~mL}$ with water, respectively. The minimum number of possible dilution steps was used for the preparation of more dilute solutions. All other common laboratory chemicals were of the best available grade.

\section{Procedure}

All the measurements were performed at $25.0 \pm 0.2{ }^{\circ} \mathrm{C}$. The change of absorbance was recorded spectrophotometrically by measuring the absorbance of the mixture solutions at $410 \mathrm{~nm}$ that is $\lambda_{\max }$ of SPR peak of AgNPs at these conditions against a reagent blank. In a typical procedure, $2.0 \mathrm{~mL}$ of $\mathrm{AgNO}_{3}$ solution $\left(2.0 \times 10^{-3} \mathrm{~mol} \mathrm{~L}^{-1}\right)$ and $2.0 \mathrm{~mL}$ of $\mathrm{KH}_{2} \mathrm{PO}_{4}$ buffer solution ( $\mathrm{pH}$ 7.0) were transferred into $10-\mathrm{mL}$ volumetric flasks. Then, appropriate volumes of SDS, CTAB, and TX-100 solutions, in the range of 0.0 to $12.0,0.0$ to 1.6 , and 0.0 to $0.5 \mathrm{mmol} \mathrm{L}^{-1}$, were added respectively to this solution and were put on magnetic stirring. After they were being mixed completely, the solutions were titrating by $1.0 \mathrm{~mL}$ of quite cold $\mathrm{NaBH}_{4}$ $\left(1.0 \times 10^{-2} \mathrm{~mol} \mathrm{~L}{ }^{-1}\right)$. Yellow colored solution confirmed the presence of AgNPs, and subsequently the solution diluted up to the volume mark with deionized water and measured its absorbance at $410 \mathrm{~nm}$.

\section{Results and discussion}

\section{Preliminary investigations of the system}

The AgNPs were prepared according to the previous reported method with minor modification (Fan et al. 2009). Chemical synthesis of AgNPs and dimensions, shape, and distribution of NPs were influenced by several parameters, such as the $\mathrm{AgNO}_{3}$ and $\mathrm{NaBH}_{4}$ concentrations, time, temperature, $\mathrm{pH}$, and surfactant concentration. All experimental parameters affecting the AgNP synthesis and CMC determination were optimized by "one at a time" method.

\section{The effect of $\mathrm{AgNO}_{3}$ concentration}

The concentration of $\mathrm{AgNO}_{3}$ as one of the reactants has an effect on the absorption of AgNPs. The effect of $\mathrm{AgNO}_{3}$ concentration on the plasmon peak of AgNPs was investigated by changing the silver ion concentration and keeping the other parameters as constant. It was found that by increasing $\mathrm{AgNO}_{3}$ concentration, more AgNPs will be produced and the plasmon peak will be increased. Figure 1 shows the absorption of AgNPs

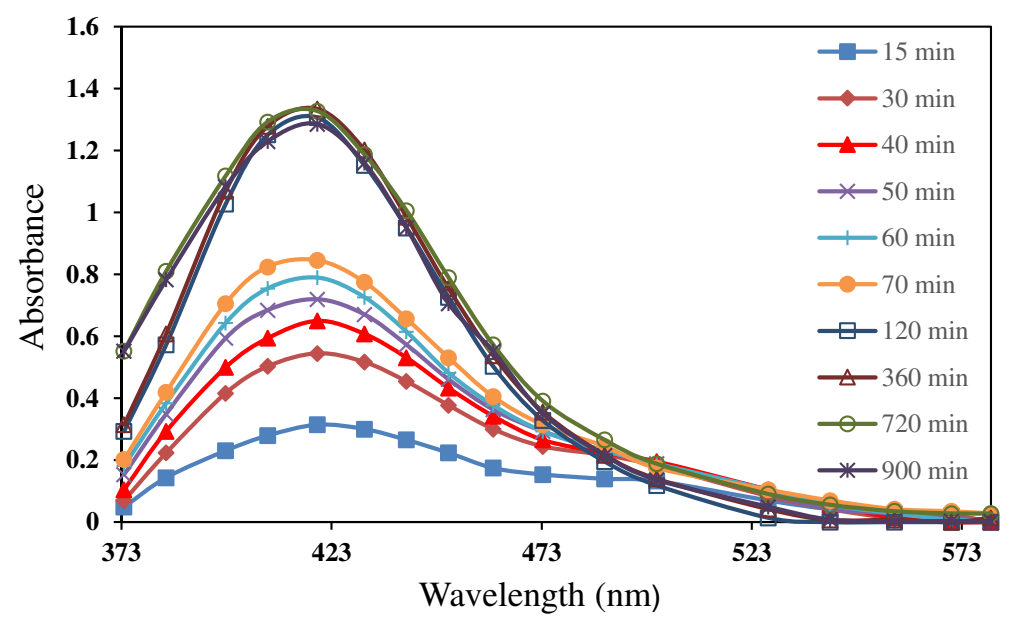

Fig. 4 Ag NPs absorption spectrum at various times. Conditions as Fig. 2 
versus different concentrations of $\mathrm{AgNO}_{3}$. From the spectrum of AgNPs, it was found that the best yellowish colored solution with more transparency and stability obtain at $2.0 \times 10^{-3} \mathrm{~mol} \mathrm{~L}^{-1} \mathrm{AgNO}_{3}$. Therefore, experiments were carried with this concentration as the optimum concentration for further studies.

\section{The effect of $\mathrm{NaBH}_{4}$ concentration}

In order to establish the effect of $\mathrm{NaBH}_{4}$ concentration on the amount of absorption of AgNPs, different concentration values of $\mathrm{NaBH}_{4}$ in the range of $5.0 \times$ $10^{-4}$ to $1.0 \times 10^{-2} \mathrm{~mol} \mathrm{~L}^{-1}$ were studied. For this purpose, the solutions containing $2.0 \times 10^{-3} \mathrm{~mol} \mathrm{~L}^{-1} \mathrm{AgNO}_{3}$ were studied. It was founded that $1.0 \times 10^{-2} \mathrm{~mol} \mathrm{~L}^{-1}$ $\mathrm{NaBH}_{4}$ was sufficient for further studies.

\section{The effect of $\mathrm{pH}$}

The effect of $\mathrm{pH}$ within the range of 7.0 to 11.0 on the SPR band intensity of $\mathrm{AgNO}_{3}$ reduction by $\mathrm{NaBH}_{4}$ was investigated in the presence of SDS, CTAB, and TX-100 in their CMC (Fig. 2). Maximum intensity of SPR peak of AgNPs at $410 \mathrm{~nm}$ was observed at pHs lower than 7.0 for each of three surfactants. The decrease in the SPR band intensity at alkaline media is probably due to the $\mathrm{Ag}_{2} \mathrm{O}$ formation. Thus, $\mathrm{pH} 7.0$ was selected as the optimum $\mathrm{pH}$ for further studies.
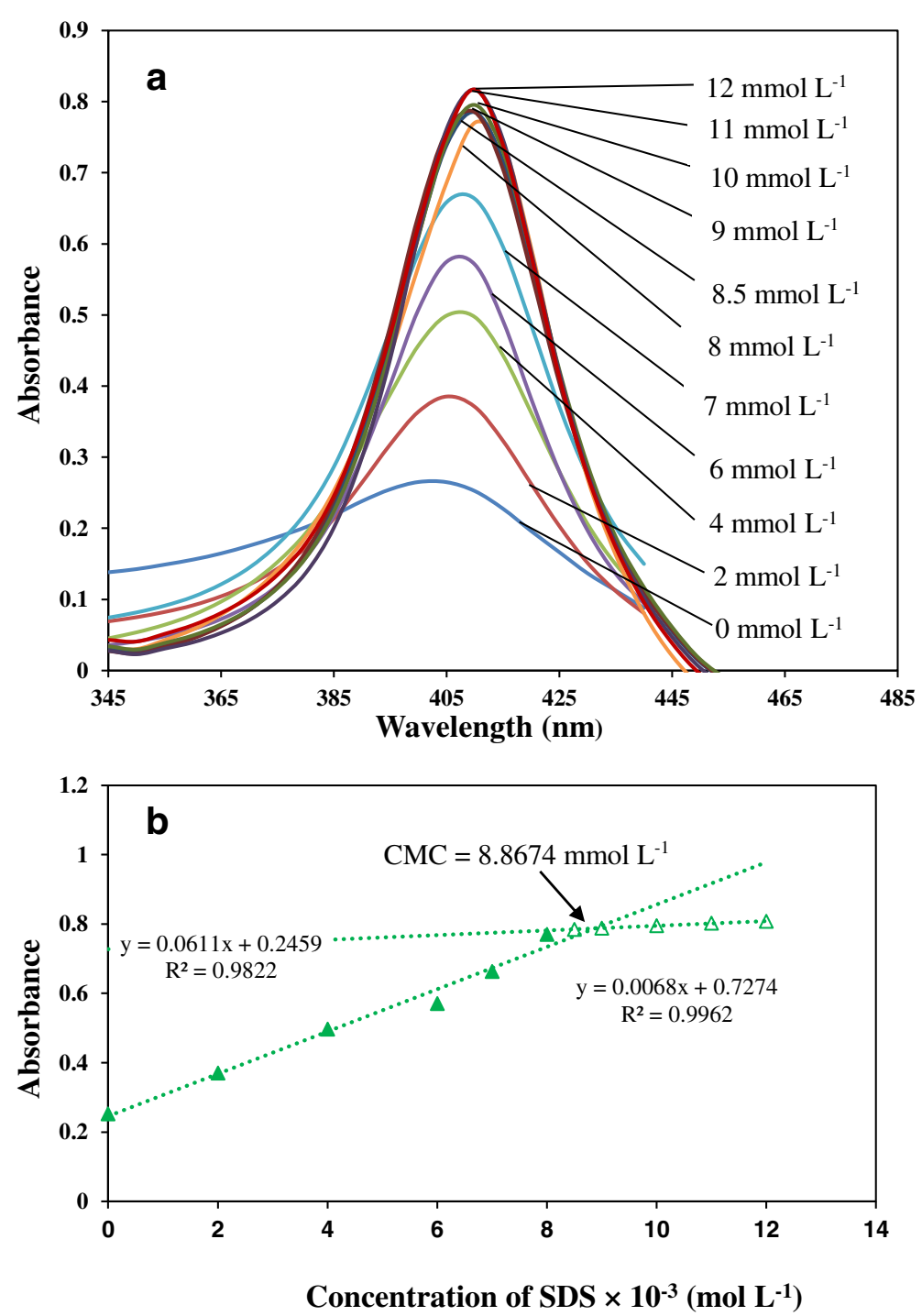

Fig. 5 The SPR spectra of AgNPs in aqueous solutions of the different concentrations of SDS (a) and plot of the absorbance intensity of AgNPs as a function of molar concentration of SDS at $410 \mathrm{~nm}$ (b). Conditions: $2.0 \mathrm{~mL} \mathrm{AgNO}$ s solution $\left(2.0 \times 10^{-3} \mathrm{~mol} \mathrm{~L}^{-1}\right) ; 1.0 \mathrm{~mL} \mathrm{NaBH}_{4}\left(1.0 \times 10^{-2} \mathrm{~mol} \mathrm{~L}^{-1}\right)$; $2.0 \mathrm{~mL} \mathrm{KH} \mathrm{PO}_{4}$ buffer solution (pH 8.0); appropriate volumes of SDS solutions of (a) 0.0, (b) 2.0, (c) 4.0, (d) 6.0, (e) 7.0, (f) 8.0, (f) 8.5, (g) 9.0, (h) 10.0, (i) 11.0 , and (j) $12.0 \mathrm{mmol} \mathrm{L}^{-1}$ 
The effect of temperature

The temperature of the solution evidently affects on the amount of AgNP absorption. The effect of temperature within the range of 15 to $45{ }^{\circ} \mathrm{C}$ on the SPR band intensity of AgNPs was investigated. The results are presented in Fig. 3. It was found that high temperatures have negative effect on the SPR band intensity of AgNPs. Therefore, the temperature of the solution was kept constant at $25 \pm 0.2{ }^{\circ} \mathrm{C}$ by a thermostatic water bath in all of the measurements.

\section{The effect of time}

The measured time includes the interval time between complete mixture of the materials and the time of obtaining spectrum from the mixture. Reduction of the silver ions, formation of AgNPs, and then their growth will begin after the addition of $\mathrm{NaBH}_{4}$ to the $\mathrm{AgNO}_{3}$ coated with cetyl trimethyl ammonium hydroxide
$(\mathrm{CTAOH})$. The reaction of AgNP formation will be continuing up to the time that $\mathrm{NaBH}_{4}$ exists in the environment to reduce the silver ions. The obtained spectra in the time range of 15-900 min were recorded and examined. Figure 4 shows after $120 \mathrm{~min}$, the absorption changes of AgNPs were insignificant, and it seemed that the reaction was completed. Therefore, 120 min was chosen as the optimum time for further studies.

\section{CMC determination of SDS, CTAB, and TX-100}

Representative surfactants of different classes including SDS, CTAB, and TX-100 as anionic, cationic, and nonionic surfactants were tested, respectively. The plots of absorbance of AgNPs versus wavelength (nm) in the presence of the different concentrations of SDS, CTAB, and TX-100 are shown in Figs. 5a, 6a, and 7a, respectively. It was observed that in the absence of surfactants, the absorption reduced and shifts to the
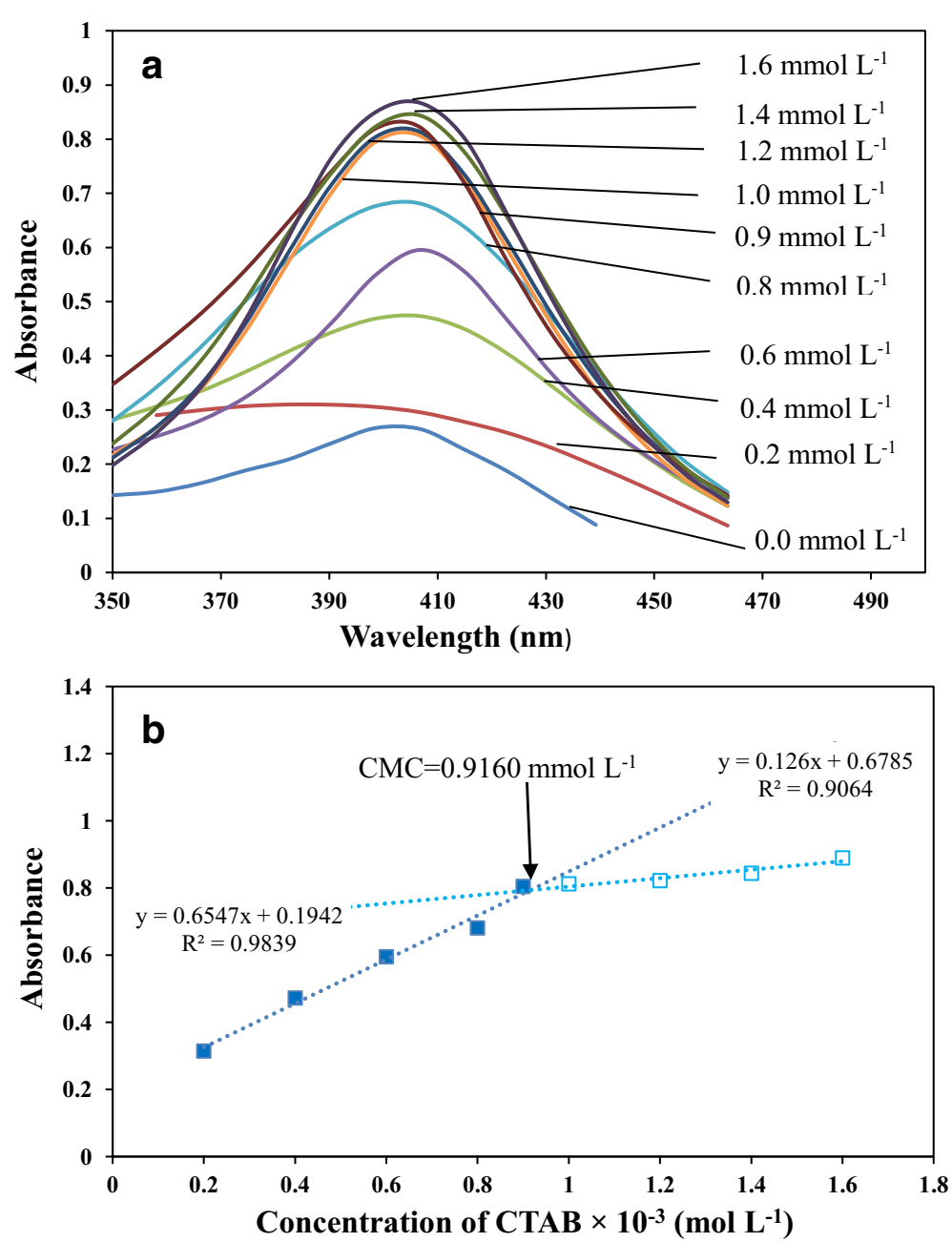

Fig. 6 The SPR spectra of AgNPs in aqueous solutions of the different concentrations of CTAB (a) and plot of the absorbance intensity of AgNPs as a function of molar concentration of $\mathrm{CTAB}$ at $410 \mathrm{~nm}$ (b). Conditions: conditions as in Fig. 1 except 2.0-mL $\mathrm{K}_{2} \mathrm{HPO}_{4}$ buffer solution (pH 9.5); appropriate volumes of CTAB solutions of (a) 0.0, (b) 0.2, (c) 0.4, (d) 0.6, (e) 0.8, (f) 0.9, (f) 1.0, (g) 1.2, (h) 1.4, and (i) $1.6 \mathrm{mmol} \mathrm{L}^{-1}$ 

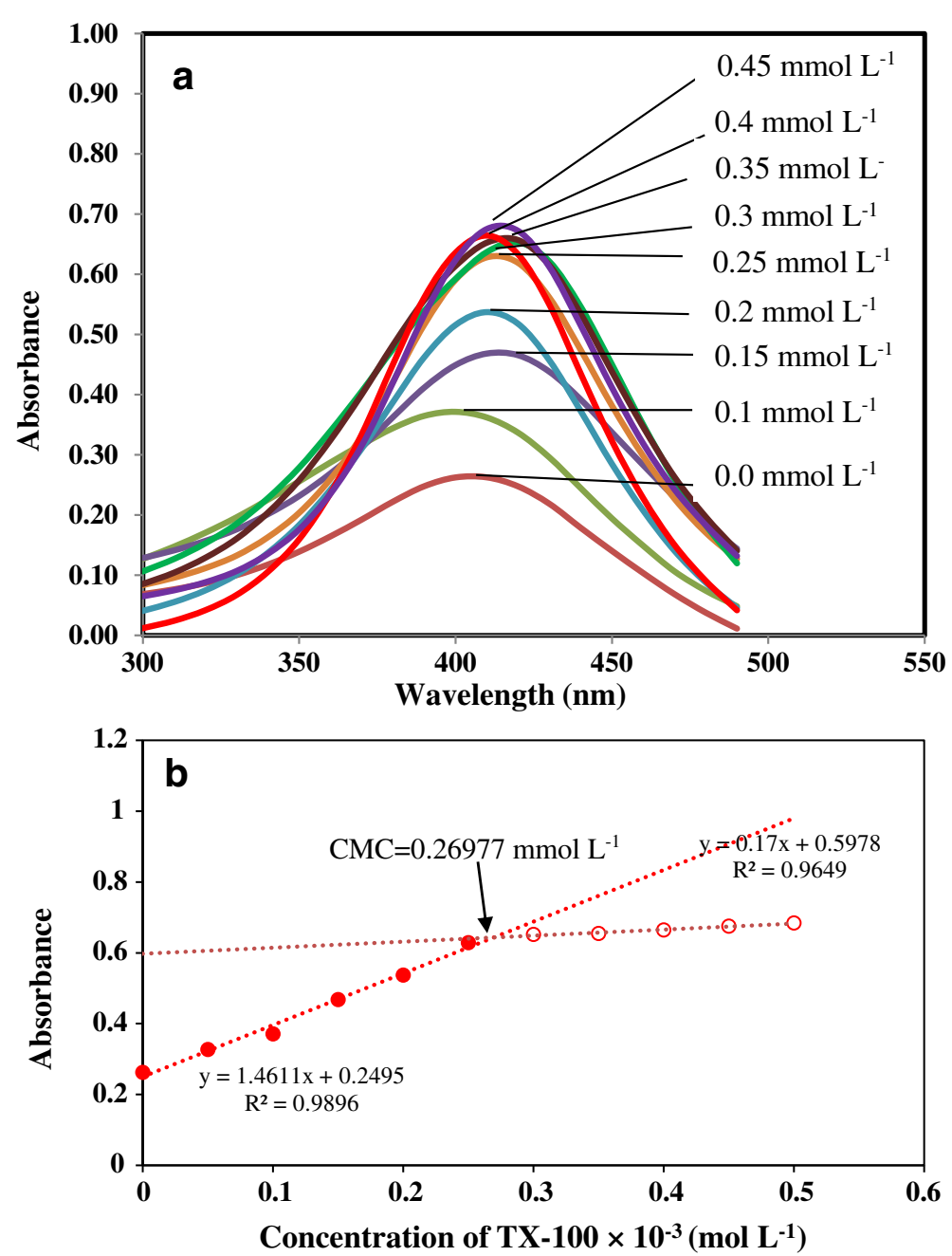

Fig. 7 The SPR spectra of AgNPs in aqueous solutions of the different concentrations of TX-100 (a) and plot of the absorbance intensity of AgNPs as a function of molar concentration of TX-100 at $410 \mathrm{~nm}$ (b). Conditions: conditions as in Fig. 1 except 2.0-mL $\mathrm{KH}_{2} \mathrm{PO}_{4}$ buffer solution (pH 7.5); appropriate volumes of TX-100 solutions of (a) 0.0, (b) 0.05, (c) 0.1, (d) 0.16, (e) 0.2, (f) 0.25, (f) 0.3, (g) 0.35, (h) 0.4, (i) 0.45, and (j) $0.5 \mathrm{mmol}^{-1}$

longer wavelengths. When surfactant concentrations increased, the size of NPs decreased and they would show higher absorption. This is the consequence of agglomeration of the AgNPs, in the absence of surfactant and isolation in the presence of surfactants when surfactant concentration increases. SDS and CTAB micelles through the electrostatic repulsion and TX100 through the spatial repulsion prevent the particles from sticking together. Increasing of surfactant concentration up to the amount of micellar formation, until the critical micellar concentration, causes increase in absorption. In this concentration, $\mathrm{Ag}^{+}$ions are surrounded by micelle and reduced to $\mathrm{Ag}^{0}$, and AgNPs are formed within the isolated reactor. Above this concentration, addition of the surfactant has not any significant effect on the AgNP absorption because nanoparticles are surrounded completely and they reach the saturation level.
In order to determine the CMC points by SPR technique, anionic, cationic, and nonionic surfactants with different concentrations were utilized, and the curves were prepared from the related SPR peaks. All of the tested surfactants showed a sharp inflection point in the curves that enabled sensitive determination of their CMC values. In addition, all displayed similar magnitude of absorbance changes and shared similar curves around their CMC independent of the charge, class of surfactant, and order of magnitude of the $\mathrm{CMC}$, indicating the universality of the method. Based on the mechanism of micelle formation, there is an inflection point in the absorbance of SPR of AgNPs versus surfactant concentration for all of the tested surfactants (Figs. 5b, 6b, and $7 \mathrm{~b}$ ). As can be seen, in all of the curves, a fracture in the slope of the surfactant concentration versus absorption at $\lambda_{\max }$ of SPR peak of AgNPs $(410 \mathrm{~nm})$ is observed, that is the CMC point. Under the optimal 
experimental conditions, CMCs for SDS, CTAB, and TX-100 using this method were $8.0 \times 10^{-3}, 9.0 \times 10^{-4}$, and $2.5 \times 10^{-4} \mathrm{~mol} \mathrm{~L}^{-1}$, respectively.

Table 1 shows a comparison of the proposed method with other reported methods. It could be seen that, the obtained CMC values of SDS, CTAB, and TX-100 by this method are in agreement very well with those determined by previously reported methods. CMCs for SDS, CTAB, and TX-100 using SPR technique (our propositional method) were $8.6 \times 10^{-3}, 9.1 \times 10^{-4}$, and $2.6 \times 10^{-4} \mathrm{~mol} \mathrm{~L}^{-1}$, respectively. The respected $\mathrm{CMC}$ values are close to voltammetry $\left(8.3 \times 10^{-3}, 8.8 \times 10^{-3}\right.$, and $\left.3.1 \times 10^{-3}\right)$, conductometry $\left(8.1 \times 10^{-3}, 9.9 \times 10^{-3}\right.$, and $\left.3.1 \times 10^{-3}\right)$, and fluorescence $\left(7.62 \times 10^{-3}, 8.9 \times 10^{-3}\right.$, and $\left.2.4 \times 10^{-3}\right)$ results. With regard to these results, it could be seen that, the obtained CMC values of SDS, CTAB, and TX-100 by this method is accommodating previously reported methods.

\section{Conclusions}

In summary, we have successfully developed a new and facile surfactant CMC determination by using SPR of AgNPs. Our goal was principally determining the CMCs of ionic and nonionic surfactants with a method that is comparable in scope and resolution to those currently obtainable from other techniques such as conductometric, voltammetric, spectrophotometric, fluorescence, and surface tension measurements. It could be seen that, the

Table 1 Comparison of the CMC of SDS, CTAB, and TX-100 between typical published methods and the proposed method in water solution

\begin{tabular}{|c|c|c|c|c|}
\hline \multirow[t]{2}{*}{ Technique } & \multicolumn{3}{|c|}{$\mathrm{CMC}, \times 10^{-3} \mathrm{~mol} \mathrm{~L}^{-1}$} & \multirow[t]{2}{*}{ Reference } \\
\hline & $\overline{\text { SDS }}$ & CTAB & $\mathrm{TX}-100$ & \\
\hline \multirow{3}{*}{$\begin{array}{l}\text { UV-visible } \\
\text { spectrophotometry }\end{array}$} & $1.0^{\mathrm{a}}$ & $0.06^{a}$ & $0.70^{a}$ & (Khamis et al. 2005) \\
\hline & $0.80^{b}$ & $0.10^{b}$ & $0.70^{b}$ & (Khamis et al. 2005) \\
\hline & $7.19^{a}$ & $0.76^{a}$ & n.d & (Mondal and Ghosh 2012) \\
\hline \multirow[t]{4}{*}{ Fluorescence } & n.d & 0.75 & n.d & (Halder 2007) \\
\hline & 7.62 & 0.89 & 0.24 & (Aguiar et al. 2003) \\
\hline & 4.22 & 0.83 & n.d & (Prazeres et al. 2012) \\
\hline & 7.96 & 0.75 & n.d & (Mondal and Ghosh 2012) \\
\hline $\begin{array}{l}\text { Resonance Rayleigh } \\
\text { scattering }\end{array}$ & 8.0 & 0.98 & n.d & (Shi et al. 2011) \\
\hline $\begin{array}{l}\text { Fiber-optic refractive } \\
\text { index }\end{array}$ & 8.1 & 0.15 & 0.21 & (Tan et al. 2010) \\
\hline \multirow[t]{2}{*}{ Conductometry } & 8.1 & 0.99 & 0.31 & (Brooks et al. 1988) \\
\hline & 8.0 & n.d & n.d & (Fuguet et al. 2005) \\
\hline \multirow[t]{2}{*}{ Voltammetry } & 8.3 & 0.88 & n.d & (Ma et al. 1998) \\
\hline & n.d & n.d & 0.31 & (Liu et al. 1999) \\
\hline SPR of AgNPs & $8.6^{\mathrm{a}}$ & $0.9^{\mathrm{a}}$ & $0.26^{\mathrm{a}}$ & This work \\
\hline
\end{tabular}

n.d not determined

${ }^{a} \mathrm{CMC}$ from absorbance changes measurements

${ }^{\mathrm{b}} \mathrm{CMC}$ from surface tension changes measurements obtained CMC values of SDS, CTAB, and TX-100 by this method agree very well with those determined by previously reported methods. Furthermore, this method is universal, sensitive, and nonadditive; accordingly, it can be used for the direct measurements of CMC without the addition of any dye or fluorescent probe. Values obtained by our simple method have accuracy which is comparable with the data obtained from more elaborate experiments.

This work was supported by the Nanoscience and Nanotechnology Research Laboratory (NNRL) of Payame Noor University of Sirjan.

\section{Competing interests}

The authors declare that they have no competing interests.

\section{Authors' contributions}

MAK, HT and AHA conceived of the original idea and design of the work. MAM and RS performed the preparation of reagents and solutions and execution of UV-Vis and SPR experiments. MAK and AHM performed the data interpretation, manuscript writing and revision. All authors read and approved the final manuscript.

\section{Author details}

'Department of Chemistry, Payame Noor University, PO Box 19395-4697, Tehran, Iran. ${ }^{2}$ Department of Chemistry \&Nanoscience and Nanotechnology Research Laboratory (NNRL), Payame Noor University, PO Box 78185-347, Sirjan, Iran. ${ }^{3}$ Department of Chemistry, Payame Noor University, Mashhad, Iran. ${ }^{4}$ Technical and Vocational University of Hazrat Roghayeh, Yazd, Iran.

Received: 11 August 2015 Accepted: 2 December 2015

Published online: 10 December 2015

\section{References}

Abdulhalim I, Zourob M, Lakhtakia A. Surface plasmon resonance for biosensing: a mini-review. Electromagnetics. 2008;28:214-42.

Aguiar J, Carpena P, Molina-Bolivar JA, Ruiz CC. On the determination of the critical micelle concentration by the pyrene 1:3 ratio method. J Colloid Interface Sci. 2003;258:116-22.

Amendola V, Bakr OM, Stellacci F. A study of the surface plasmon resonance of silver nanoparticles by the discrete dipole approximation method: effect of shape, size, structure, and assembly. Plasmonics. 2010;5:85-97.

Brooks SH, Berthold A, Kirsch BA, Dorsey JG. Flow-injection system for determination of critical micelle concentration of ionic and nonionic surfactants. Anal Chim Acta. 1988:209:111-21.

Fan Y, Liu Z, Wang L, Zhan J. Synthesis of starch-stabilized Ag nanoparticles and $\mathrm{Hg}^{2+}$ recognition in aqueous media. Nanoscale Res Lett. 2009:4:1230-5.

Fuguet E, Rafols C, Roses M, Bosch E. Critical micelle concentration of surfactants in aqueous buffered and unbuffered systems. Anal Chim Acta. 2005;548:95-100.

Halder M. Determination of the critical micellar concentration (CMC) of a cationic micelle from stokes shift data. Chem Educator. 2007;12:33-6.

Homola J. Surface plasmon resonance based sensors. Berlin and Heidelberg, Germany: Springer = Verlag; 2006 .

Khamis M, Bulos B, Jumean F, Manassra A, Dakiky M. Azo dyes interactions with surfactants. Determination of the critical micelle concentration from acidbase equilibrium. Dyes Pigm. 2005;66:179-83.

Lin CE, Lin KC. Determination of critical micelle concentration and interactions between cephalosporins and charged surfactants. J Chromatogr A. 2000;868:313-6.

Liu T, Guo R, Gm S. Determination of the micellar properties of Triton X-100 by voltammetry method. J Disp Sci Technol. 1999;20:1205-21.

Ma C, Li G, XU Y, Wang H, Ye X. Determination of the first and second CMC of surfactants by absorptive voltammetry. Colloids Surf A. 1998;143:89-94.

Mondal S, Ghosh S. Role of curcumin on the determination of the critical micellar concentration by absorbance, fluorescence and fluorescence anisotropy techniques. J Photochem Photobio B: Biology. 2012;115:9-15.

Nesmerak K, Nemcova L. Determination of critical micelle concentration by electrochemical means. Anal Let. 2006;39:1023-40. 
Pattnaik P. Surface plasmon resonance applications in understanding receptorligand interaction. J Appl Biochem Biotech. 2005;126:79-92.

Prazeres TJV, Beija M, Fernandes FV, Marcelino PGA, Farinha JPS, Martinho JMG. Determination of the critical micelle concentration of surfactants and amphiphilic block copolymers using coumarin 153. Inorg Chim Acta. 2012;381:181-7.

Racaud C, Serrano KG, Savall A. Voltammetric determination of the critical micellar concentration of surfactants by using a boron doped diamond anode. J Appl Electrochem. 2010;40:1845-51.

Ren J, Tilley RD. Preparation, self-assembly, and mechanistic study of highly monodispersed nanocubes. J Am Chem Soc. 2007;129:3287-91.

Shi Y, Luo HQ, Li NB. Determination of the critical premicelle concentration and second critical micelle concentration of surfactants by resonance Rayleigh scattering method without any probe. Spectrochim Acta A. 2011;78:1403-7.

Simonović BR, Momirović M. Determination of critical micelle concentration of bile acid salts by micro-calorimetric titration. Mikrochim Acta. 1997;127:101-4.

Tan CH, Huang ZJ, Huang XG. Rapid determination of surfactant critical micelle concentration in aqueous solution using fiber-optic refractive index sensing. Anal Biochem. 2010;401:144-7.

Topel Ö, Acar Çakır B, Budama L, Hoda N. Determination of critical micelle concentration of polybutadiene-block-poly(ethyleneoxide) diblock copolymer by fluorescence spectroscopy and dynamic light scattering. J Mol Liq. 2013;177:40-3.

Tran CD, Yu S. Near-infrared spectroscopic method for the sensitive and direct determination of aggregations of surfactants in various media. J Colloid Interface Sci. 2005;283:613-8.

Van Os NM, Haak JR, Rupert LAM. Physico-chemical properties of selected anionic, cationic and nonionic surfactants. Amsterdam: Elsevier; 1993.

Yan JF, Palmer MB. A nuclear magnetic resonance method for determination of critical micelle concentration. J Colloid Interface Sci. 1969;30:177-82.

Yong K, Swihart MT, Ding H, Prasad PN. Preparation of gold nanoparticles and their applications in anisotropic nanoparticle synthesis and bioimaging. Plasmonics. 2009:4:79-93.

Zhu Q, Huang L, Su J, Liu S. A sensitive and visible fluorescence-turn-on probe for the CMC determination of ionic surfactants. Chem Commun. 2014;50:1107-9.

Zielinski R, Ikeda S, Normura H, Kato S. Adiabatic compressibility of alkyltrimethylammonium bromides in aqueous solutions. J Colloid Interface Sci. 1987;119:398-408.

\section{Submit your manuscript to a SpringerOpen ${ }^{\circ}$ journal and benefit from:}

- Convenient online submission

- Rigorous peer review

- Immediate publication on acceptance

- Open access: articles freely available online

- High visibility within the field

Retaining the copyright to your article 